\title{
Childhood Botryoid-Type Embryonal Rhabdomyosarcoma
}

National Cancer Institute

\section{Source}

National Cancer Institute. Childhood Botryoid-Type Embryonal Rhabdomyosarcoma. NCI Thesaurus. Code C35574.

A morphologic variant of embryonal rhabdomyosarcoma occurring in children. The tumor arises from organs with a mucosal epithelial surface. It is characterized by the formation of a cambium layer in the affected tissue and polypoid nodules within an abundant myxoid stroma. 